\title{
Improved investment in mental health services: value for money?
}

\author{
David Goldberg
}

\section{Background}

This paper examines what has been achieved in the specialist mental health services by the vastly increased health expenditures that the National Health Service (NHS) has enjoyed in the past 5 years.

\section{Aims}

To describe the way money has been spent in specialist mental health services and examine why problems remain after such admirable changes to already available resources.

\section{Method}

Changes in staff employed by mental health services, where the extra staff are deployed, and patterns of expenditure within the whole service and within community mental health teams are examined.

\section{Results}

Some of the new expenditure has been well spent, and has produced improvements in the service. However, one must also take account of the costs of the greatly increased numbers of managers, who impose two sorts of costs: that of their own salaries, and the opportunity costs of front-line staff having to attend meetings and write reports rather than seeing patients. Throughout the rest of the NHS, money has been wasted on needless reorganisations, on consultant and general practitioner contracts, and on information technology that has so far failed to deliver tangible advantages.

\section{Conclusions}

The emphasis on central control undermines local initiatives and wastes resources. Some central control is inevitable, but policies need to be developed in collaboration with clinicians. At local level, expenditure by primary care trusts and mental health trusts also needs to be scrutinised by committees that should include representatives of front-line mental health staff.

\section{Declaration of interest}

None.
Although there have been vast increases in expenditure ${ }^{1}$ great problems remain in the mental health services. This is despite the fact that the UK spends a greater proportion of its health expenditure on mental health than any other European country and should, therefore, have a mental health service which leads the way.

\section{Method}

Documents available to the public on various websites were examined, together with papers on public expenditure on health published by the King's Fund, ${ }^{1,2}$ the National Audit Office, ${ }^{3}$ the Treasury, ${ }^{4}$ the National Survey of Investment ${ }^{5,6}$ and the House of Commons. ${ }^{7}$

\section{Results}

It should be made clear at outset that there are large variations in the amount of mental health spend per head of population each year, ranging from a maximum of $£ 174-207$ in the four London areas - North Central, South East, North West and South West - to $£ 128$ in Greater Manchester, and Kent and Medway. ${ }^{2}$

\section{Money (largely) well spent}

The 2062 additional consultant psychiatrists shown in Table 1 represent a $48 \%$ increase. In addition, there have been substantial increases in clinical psychologists and care workers, and smaller increases in occupational therapists and nurses. The greatly increased numbers of managers and administrators will be discussed in the next section.

The deployment of these new staff is of great interest, as what are now termed 'new' community mental health teams (early intervention, assertive outreach, and crisis resolution services) have gained most from extra staff. 'Conventional' community mental health teams have lost both nurses and social workers but, on the other hand, have gained the largest group of new consultants. In-patient units have also acquired many new consultants and psychologists, but lost both social workers and nurses (Table 2).

The greatest number of new consultants has been, appropriately, in the adult mental health service, where there are now three consultants for every two that held a post in 1990, while the greatest proportionate increase has been in old age psychiatry, followed closely by forensic psychiatry (Table 3 ). There has been a large investment in forensic services, presumably following ministerial anxiety about violence by people with a mental illness in public places.

It is of interest to compare numbers of trainees with numbers of consultants, as the figures are alarming (Fig. 1). Numbers of senior house officers increase year on year against a fixed number of specialist registrars. The effect of this is to recreate the career bottleneck that existed in the 1970s, and even the fact that many

\begin{tabular}{lrc|}
$\begin{array}{l}\text { Table } 1 \\
\text { 2001-2006 }\end{array}{ }^{6}$ & $n$ & Increase, \% \\
Staff employed & 2062 & 48 \\
Consultants & 539 & 34.4 \\
\hline Managers & 1200 & 25.5 \\
\hline Administrators & 501 & 26 \\
\hline Clinical psychologists & 10885 & 21 \\
\hline Care workers & 411 & 15 \\
\hline Occupational therapists & 3258 & 10 \\
\hline Psychiatric nurses & -135 & $(-3)$ \\
\hline (Fewer) social workers & & \\
\hline
\end{tabular}




\begin{tabular}{|c|c|c|c|c|c|}
\hline Setting & Doctors & Psychologists & Social workers & Nurses & Managers \\
\hline In-patient units & 343 & 47 & -12 & -9 & 13 \\
\hline Out-patient units & 40 & 36 & 0 & 40 & 105 \\
\hline Secure units (all) & 266 & 10 & 65 & 1911 & 243 \\
\hline Conventional CMHTS & 600 & 22 & -635 & -749 & 131 \\
\hline New CMHTS & 415 & 171 & 549 & 3289 & 673 \\
\hline Total (these five only) & 1664 & 286 & -33 & 4482 & 1165 \\
\hline
\end{tabular}

\begin{tabular}{|c|c|c|}
\hline Subject area & Extra posts & $\begin{array}{c}\text { Increase } \\
\text { 1990-2006, \% }\end{array}$ \\
\hline Learning disability & 31 & 119 \\
\hline Psychotherapy & 23 & 133 \\
\hline Child and adolescent psychiatry & 157 & 147 \\
\hline Adult mental illness & 658 & 158 \\
\hline Forensic psychiatry & 139 & 299 \\
\hline Old age psychiatry & 389 & 580 \\
\hline
\end{tabular}

senior house officers do not intend to become fully trained psychiatrists is not sufficient to allow for this imbalance. These changes in the mental health workforce can also be seen in investment, which includes far more than the expense of new staff.

Table 4 shows a selection of mental health services whose funding has changed the most between 2002 and 2006. The middle column 'Increase in budget 2005/2006' is taken from Finance Mapping, ${ }^{6}$ but on its own is misleading, since it fails to take account of the size of the budget in 2002 (shown in the left column). The column 'Extra investment' is the difference between what would have been spent had expenditure continued at 2002 levels, and the sum of what was actually spent between the years 2002 and 2006. If total expenditure on the National Health Service


million of extra money devoted to mental health is a truly niggardly sum. Within that sum, although the extra $£ 106$ million spent on community mental health teams is the third largest item of extra expenditure, it only represents a 9\% increase over 2002.

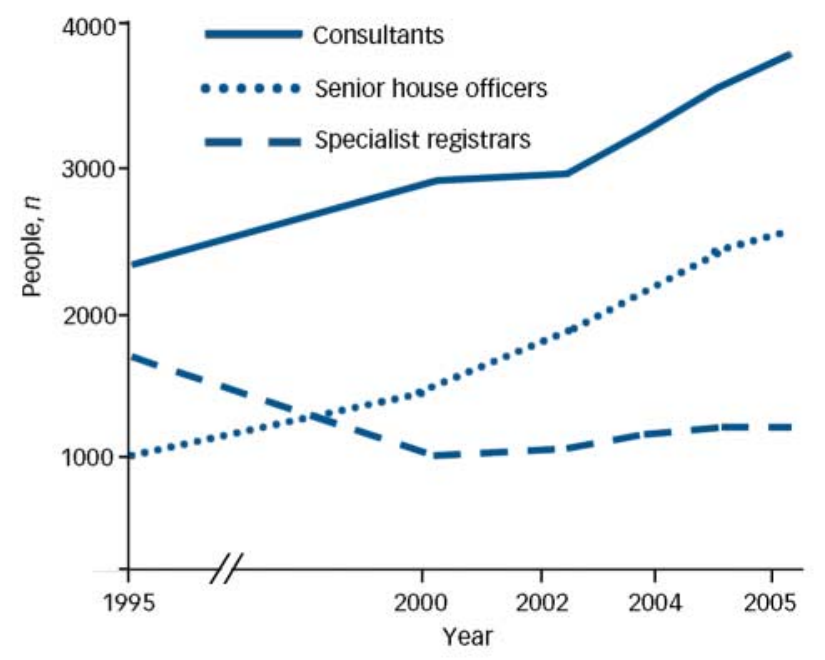

Fig. 1 Numbers of consultant psychiatrists, specialist registrars and senior house officers, 1995-2005.
The figures in this table may overestimate the increase in expenditure on regional medium secure facilities, as data for 2002 were incomplete for this item; however, it is unlikely to be by very much, since the National Survey of Investment ${ }^{6}$ gives an even higher increased expenditure on these units (an extra $\mathfrak{E} 628$ million on what are described as 'secure and high dependency' units). They confirm the high extra payments to what are termed 'access and crisis services'.

The year-on-year changes in expenditure on new service areas are shown in Fig. 2, where home treatment has now overtaken assertive outreach, and early intervention is beginning to rise steadily. Over the same period, the number of mental health beds has been reduced by 2118 for acute mental illness and 946 for longstay beds; however, the number of new forensic psychiatry beds has increased by 753 (Fig. 3). This should have produced large amounts of money to improve the mental health service since the main reason

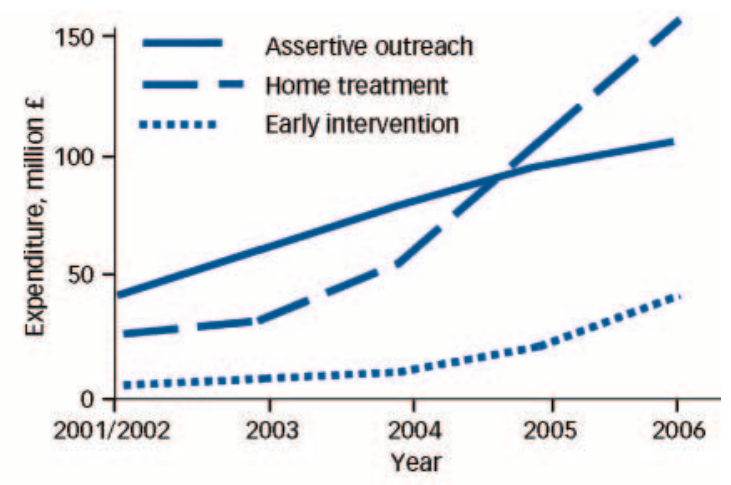

Fig. 2 Cash investment in priority service areas, 2001-2006. Data collected from Appleby. ${ }^{2}$

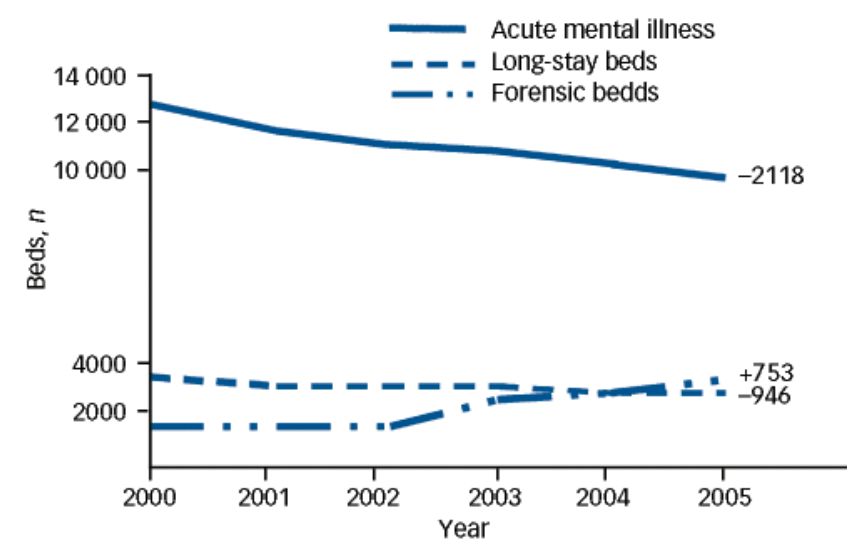

Fig. 3 Changes in the number of in-patient mental health beds, 2000-2005. Data collected from the House of Commons. 
Table 4 Expenditure on selected mental health services, 2002-2006. All prices uplifted to constant 2005 prices. (Data collected from Mental Health Strategies, National Mental Health Finance Mapping 2003-2005; G. Glover, personal communication, 2007.)

\begin{tabular}{|c|c|c|c|}
\hline Service & $\begin{array}{c}\text { Out-turn } 2002 / 2003, \\
\text { million } f\end{array}$ & $\begin{array}{c}\text { Increase in budget } \\
2005 / 2006, \%\end{array}$ & $\begin{array}{l}\text { Extra investment, }{ }^{a} \\
\text { million } f\end{array}$ \\
\hline Crisis resolution & 36.6 & 297 & 186.0 \\
\hline Regional medium secure & 88.3 & 173 & 169.4 \\
\hline Community mental health teams & 366.2 & 9 & 106.4 \\
\hline Assertive outreach & 50.7 & 70 & 74.5 \\
\hline Local low secure services & 81.2 & 78 & 50.1 \\
\hline Early intervention & 7.5 & 426 & 48.6 \\
\hline Primary care mental health workers & 6.3 & 251 & 18.3 \\
\hline Prison psychiatric services & 3.2 & 215 & 13.2 \\
\hline Secure high dependency & 57.8 & 38 & 4.0 \\
\hline Residential rehabilitation & 142.0 & 0 & -14.7 \\
\hline Total mental health expenditure & 3.38 billion & 22 & 470 \\
\hline
\end{tabular}

for further bed closures is to generate funds, especially as admissions are now mainly for dangerous and disruptive patients.

\section{Money (largely) wasted}

In 2000, there were 6275 managers and administrators in mental health services, and 99052 other staff - a ratio of 1 manager/ administrator to 15.7 staff. These numbers have now grown to 12013 and $116035,{ }^{9,10}$ a ratio of 1:9.7. Something is seriously wrong.

My work over the past 21 years as a non-executive director of three NHS trusts has involved me in meeting many managers, and I can attest that the great majority of them are able and hardworking people, doing a conscientious job. The problem is that in many cases the job doesn't need doing - it is imposed upon them by the Department of Health. Each month, a new regulation with a necessity to report on some aspect of the service is introduced, and the luckless manager has no option but to do it. Professor Calum Paton, until recently Chairman of an NHS trust, writes 'there are now so many commands, controls and systems in place, laid on top of one another that the chances of the NHS working properly are almost zero.' ${ }^{11}$

However, the extra cost to the NHS cannot be computed by summing the extra managerial salaries, but must take the count of the extra opportunity cost imposed upon the NHS. Doctors, psychologists and nurses who might be looking after patients spend a growing proportion of their working week attending meetings with numerous managers, attending clinical governance meetings, carrying out audit activities, in addition to filling in survey forms and reporting on how they spend their time. Of the 5738 additional managers appointed in mental health services since 2001, let us make the generous assumption that half of them are necessary to take care of the 16983 non-managerial staff. If we make a rough calculation that on average each receives $£ 40000$ a year, this only accounts for $£ 114$ million, which on its own cannot account for the financial crisis in the NHS described by the King's Fund ${ }^{2}$ and publicised by the Secretary of State. No one has so far calculated the opportunity cost of being strangled by overmanagement, and it hardly seems likely that such a project would receive government support.

\section{Wasted money in the rest of the NHS}

Part of our problem has to be found outside mental health services, in patterns of expenditure in the rest of the NHS. In the NHS as a whole, the greatest percentage increase in staff numbers has been in managers. ${ }^{2}$ Although there are now 20998 more doctors in the NHS, between 2000 and 2005 there were 13296 new managers and senior managers, and 24422 of what the Department of Health mysteriously describes as 'central functions' staff (total: 42896 new administrative staff). Four costly projects of the Department of Health are delivering very little health gain for the population, and precious little for those that designed them. These are the costs of successive NHS reorganisations, the costs of new information technology, and the costs of consultant and general practitioner (GP) contracts.

It is difficult to understand how it was not foreseen that there was not the necessary trained workforce to run the 303 primary care trusts. So, the 303 primary care trusts in 2002 were reduced to 152 in 2006. Eight regional health authorities became 28 strategic health authorities in 2002, now reduced to 10 . Once more, no one knows the true costs of doing this, but they have been estimated as $\mathfrak{E} 1.5$ billion by Paton, and $\mathfrak{E} 3$ billion by the Health Select Committee. These are wild guesses and it is not in the Department of Health's interest to find out a more exact figure.

The National Audit Office has estimated the costs of the programme for new information technology in the NHS as $£ 12.4$ billion over 10 years, ${ }^{12}$ but the Health Minister, Lord Warner, has been more candid and has guessed $£ 20$ billion over the same period. Since the programme began about 3 years ago, even the lower figure of the National Audit Office gives a total of $£ 3.6$ billion already spent. The reason given in favour of this new technology is to provide clinicians with relevant parts of a patient's record electronically regardless of where the patient is being cared for. However, the programme has not so far delivered anything in the mental health field and the normal process of investment in upgrading information systems by mental healthcare providers has been blocked pending the arrival of the new systems. While budgets for trusts are predetermined, clearly there is no upper limit on central spending, but there should be.

Compared with the above estimated costs, the costs of the new doctors' contracts are relatively small: about $\mathfrak{E} 0.95$ billion for the

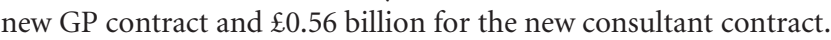
While doctors naturally welcome these generous pay rises, the benefits to patients are invisible. General practitioners now do less work for more money, and patients are often seen at night by a nurse where previously they would have seen a doctor. The consultant contract was designed - with the usual visceral dislike of doctors coupled with a general ignorance about how long their hours are - to give managers more control over medical decisions. Fortunately, it has not done so.

To these costs must be added the opportunity costs of diverting front-line clinical staff away from patient contact towards 
administrative and audit tasks. These wasteful uses of public monies need to be mentioned because there is general bewilderment about how so much extra money can have bought us so little especially as mental health is a small, but important, part of the NHS.

\section{Discussion}

The explanation for the paradox that we started with is that by no means all the money has been wasted: pay-rises agreed by the Department of Health, but previously unfunded, have now been paid. In the whole NHS, an extra $£ 6.6$ billion has been spent on new staff and paying off these debts, with welcome expenditure

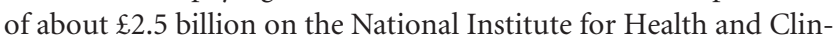
ical Excellence and drug recommendations, and $£ 1.1$ billion on capital costs. New buildings that have been provided are also a welcome development, although there is still a great need for refurbishing old buildings that greatly outnumber the new. The development of new community health services is also welcomed, although some of the changes still require proper evaluation.

However, in many of our inner cities community mental health teams are seriously short-staffed, yet the incredible amount of additional money should have allowed us to consign these difficulties to the past. In a previous paper, ${ }^{13}$ I described users' views about these innovations and they are generally welcomed; however, there is great and understandable dissatisfaction with old buildings and short-staffed community mental health teams.

Much of the waste is imposed upon trusts by the Department of Health, and much more is caused by political decisions by ministers, who either appear convinced that the answer to problems in the NHS is yet another administrative reorganisation, or who commit the NHS to major policy changes (e.g. foundation trusts, new arrangements for training junior doctors, and functional teams) on slight evidence. There have also been important, farreaching changes in primary care mental health services which require a separate, full evaluation.

At the time when data for this paper were collected, there seemed no end in sight to the damage which the Blair/Hewett axis was causing to the NHS. While the promise of the abandonment of some national targets is very welcome, the idea that this is the end of central control would represent the triumph of hope over experience. Those hoping that foundation trusts would signal a new independence from central control now find that in place of scrutiny by the strategic health authority comes scrutiny by Monitor, an independent regulator (http://www. monitor-nhsft.gov.uk/).

\section{Implications}

Centrally imposed policies are inevitable in a centrally funded service - there can be no quarrel with that. The basic problem is that such policies have not been evolved in collaboration with representatives responsible for the service at ground level, but rather have been invented by those far removed from the realities of day-to-day life in clinics around the country.

Further, there is a limit to the extent to which detailed policies should be imposed from central government. Local trusts must be left with latitude in how services in particular places are developed. At present, while lip service is paid to local initiatives, central requirements overwhelm them. Annual reports, providing information required by the Department of Health, might be provided by sampling chosen weeks in the year rather than collecting information about every item of service during the year. Both primary care trusts and users' groups could provide feedback to the Department of Health about their local hospitals, and these could provide information detailing what they were proposing to do in response.
It seems likely that in future there will be an even greater emphasis on the use of economic levers to control local developments. It is certainly preferable for local spending decisions to be made by primary care trusts than being centrally imposed, but once more there need to be checks and balances which allow consideration of the desirable services made available to the local population. This requires a discussion between local clinicians if a local service will have to be closed in order to balance a budget, with a paper submitted to the primary care trust before a final decision is made. It is scandalous that, at a time when more money than ever is available to the NHS, clinical services for patients have been cut back or discontinued in order to balance local budgets.

At local trust level, decisions about expenditure should be approved by a committee composed of front-line clinical staff and management with non-executive board members represented. There are sums spent on management consultants, pay-offs to retiring managers, and training days for management that are never scrutinised by clinical staff - they should be. Such a committee should be responsible for the trust's forward investment policy, so that deficiencies in current services can be remedied.

David Goldberg, FRCPsych, Professor Emeritus, Institute of Psychiatry, King's College London, De Crespigny Park, London SE5 8AF, UK. Email: spjudpb@hotmail.com

First received 11 Jul 2007, final revision 8 Oct 2007, accepted 18 Oct 2007

\section{Acknowledgements}

Dr Gyles Glover advised on the data available and procured and processed some data quoted. Both he and Professor Stefan Priebe very kindly commented on the text.

\section{References}

1 Appleby J, Harrison A. Spending on Health Care: How Much Is Enough? King's Fund, 2006.

2 Appleby J. Where's the Money Going? King's Fund, 2006. http:// www.kingsfund.org.uk/publications/briefings/wheres_the.html

3 National Audit Office. National Audit Office Value for Money Report. National Audit Office, 2007. http://www.nao.org.uk/publications/nao_reports/ chronindex.asp?type=vfm.

4 Wanless D. Securing Our Future Health: Taking a Long-Term View - Final Report. HM Treasury, 2002. http://www.hm-treasury.gov.uk/ Consultations_and_Legislation/wanless/consult_wanless_final.cfm.

5 Department of Health. 2006-2007 National Survey of Investment in Mental Health Services. Department of Health, 2007. http://www.dh.gov.uk/en/ Publicationsandstatistics/Publications/PublicationsStatistics/DH_079667

6 Mental Health Strategies. The 2005/2006 National Survey of Investment in the Mental Health Services. Department of Health, 2007. http:// www.dh.gov.uk/en/Publicationsandstatistics/Statistics/DH_4134717.

7 House of Commons Hansard Written Answers. Mental Health Services. House of Commons, 2006. http://www.publications.parliament.uk/pa/ cm200607/cmhansrd/cm061214/text/61214w0027.htm

8 Glover G, Barnes D. Mental Health Service Provision for Working Age Adults in England 2001. University of Durham, 2002.

9 Department of Health. NHS Hospital and Community Staff (HCHS). Department of Health, 2007. http://www.dh.gov.uk/en/ Publicationsandstatistics/Statistics/StatisticalWorkAreas/Statisticalworkforce/ DH_4087066

10 The Information Centre. NHS Staff 1995-2005. The Information Centre, 2006. http://www.ic.nhs.uk/statistics-and-data-collections/workforce/nhsnumbers/nhs-staff-1995-2005

11 Calum P. I refuse to be a scapegoat for the government's NHS failures. The Guardian 2006; 22 September. http://www.guardian.co.uk/comment/story/ $0,1878189,00$. html

12 National Audit Office. National Audit Office Value for Money Report: Executive Summary. The National Programme for IT in the NHS. National Audit Office, 2007. http://www.nao.org.uk/publications/nao_reports/05-06/ 05061173es.htm

13 Goldberg DP. The state of British psychiatry. Prog Neurol Psychiatry 2006; 10: $11-18$. 